\title{
PEDAGOGY: THE SILENT PARTNER IN EARLY YEARS LEARNING
}

\begin{abstract}
This paper sets out to look critically at the influences on pedagogy in early years education, at the ways in which it is enacted in practice and the pedagogical perspectives held by practitioners. The aim of the paper is to explore the current state of understanding and suggest areas to be included in an agenda for future research. The factors that influence practitioners' actions are reviewed and the consensus around child-centredness and play is challenged. Findings from two studies of pedagogy in action in the early years are presented and examined in terms of socio-cultural theory and its implications for practice. The first of these studies draws attention to the varied nature of pedagogical interactions that support learning while the second looks at the experience of pedagogical innovation. The need for researchers and practitioners to find effective ways of communicating and working together is stressed throughout the paper.
\end{abstract}

\section{Key Words}

pedagogy, early years settings, socio-cultural theory, agenda for early years research 


\section{Introduction}

In this paper I will focus on the pedagogical strategies and practices typically employed in early years settings, exploring the current state of understanding and suggesting areas for inclusion in an agenda for future research. The aim is to challenge the 'taken for granted' and suggest issues for exploration and empirical study, rather than offering solutions or direct recommendations for policy or practice.

In a field such as early years where the landscape of provision is shifting and variously defined and the range of titles given to those who educate and care for young children can vary from one local authority to another it is necessary to begin by defining the terms being used. In this paper I am concerned with provision for children aged from about three to six years old. In the UK this means being concerned with preschool education and care settings and the first years in primary school. However, the arguments about pedagogy which will evolve in this paper are pertinent in any setting for three- to six-year olds. I will use the term practitioner to refer to all those who work with young children, whatever their qualification route or training experiences. In addition, it is important at the outset to be clear that while this paper focuses on the role of practitioners as actors in the learning process this is not to deny the active role of young children and the learning that they bring from family and community to the early years setting. It should be understood in what follows that young children are constructed as agentic partners in the learning, social and emotional interactions they experience in group settings and that they have distinct preferences and interests which may be influenced, but not defined, by the adults they encounter at home or in early years settings (e.g. Stephen, McPake, Plowman and Berch-Heyman, 2008; Stephen, 2003; Gmitrova, Podhajeck and Gmitrov, 2009).

The experience of conducting two particular empirical studies has influenced the arguments and suggestions for further exploration presented in this paper. These studies will be introduced here and the findings referred to later as illustrations and provocations. The first of these studies was Interplay, an ESRC-funded study which aimed to enhance young children's engagement with technology in preschool settings (Stephen and Plowman, 2008; Plowman and Stephen, 2007). Although it was concerned with children's engagement with technological resources, we argue that our findings can be applied to any of the other activities and resources typically found in preschool environments e.g. water play, construction or number puzzles. The study adopted an explicitly socio-cultural perspective and was carried out in two clusters of four preschool settings. It involved working intensively with 14 practitioners over the course of one school year.

In Interplay we investigated playroom pedagogy in relation to technological resources through a process of guided enquiry (Stephen and Plowman, 2008). This cyclical process began with the researchers making observations of children's encounters with a wide range of technologies and sharing these vignettes and video recordings with practitioners from the settings involved. In response we asked practitioners to plan an intervention in their setting and make observations of children's engagement with the technology or new programmes they wished to introduce. The practitioners shared their observations with the researchers and with each other and collected examples of children's progress which the research team used to analyse the kind of learning taking place. While the practitioners put their chosen interventions into practice the research team observed and videoed in the playroom. In each setting the plan-act-review cycle of guided enquiry was repeated twice in the course of the year. Guided enquiry allowed practitioners to comment on and identify important features of their own practices and avoided the 'deficit' approach to educational change that imposes solutions. Videos and photographs of 
playroom encounters with technologies, observations and field notes, interviews with practitioners and accounts of the practitioner review meetings, along with evidence from practitioners about learning episodes, gave us a rich and diverse data set.

The second study (part of the Scottish Applied Educational Research Programme) explored the shift to what was described as 'active learning' at the beginning of primary school. This policymaker-driven change in pedagogy was studied in two local authority areas where local policymakers and managers of provision had chosen to amend their pedagogical expectations during a time of curriculum change (Stephen, Ellis and Martlew, 2009). We explored the impact of the shift to active learning in six Primary 1 classrooms. (In Scotland Primary 1 is the first year of primary school which children enter when they are from four years 6 months old to five years 6 months old.) We had five sources of data in this study: interviews with teachers; interviews with school managers and local authority representatives; interviews with parents; conversations with children; and repeated systematic observations in each classroom. The observations were carried out on four occasions over the school year. Two approaches to observation were adopted. We completed timed observations of focal children across each observation period and periodic scans of whole class activity, noting what children and adults were doing, who initiated the activities and the ways in which children were engaged in the classroom.

\section{Considering pedagogy}

Discussions about the meaning of pedagogy in the Anglo-American tradition can become stuck in the debate about whether the behaviours in question are (or should be) based on a set of principles or rules or are more relevantly described as art or craft, changing and adapting to the context and individuals involved. Pedagogy has been described as the 'act and discourse of teaching' (Alexander, 2004), the application of professional judgements or 'any conscious activity by one person designed to enhance learning in another' (Watkins and Mortimer, 1999). Pedagogical practices observable in early years settings range from the didactic interactions more typically associated with teaching, through modelling, prompting exploration, questioning, scaffolding specific skill acquisition and nurturing a child's disposition to learn.

In the UK policymakers, managers of early years provision and practitioners are now comfortable with considering their practice in relation to a formal written curriculum. Each of the four national educational systems in the UK has a well developed curriculum, based on explicit and implicit values and ideas about the goals of early years education. Practitioners working in the public sector, and in voluntary and private settings in partnership with local authorities, expect the national curriculum to be at the heart of their provision, practice and planning and they can identify how their setting fulfils curricular expectations (Stephen, Brown and Cope, 2001). However, asking about pedagogy still disturbs some practitioners who find it more difficult to articulate how they act to support learning. In this review we will begin by considering the place of pedagogy in early years provision before moving on to consider the influences on pedagogical practices in early years settings

Both Simon (1981) and Alexander (2004) have raised questions about the absence of any tradition of systematic pedagogy in practice or policymaking in primary education in England, despite a growing body of research evidence about teaching and about how children learn. A study of newly qualified secondary and primary school teachers in Scotland found that in over 1,000 pages of interview transcripts 
there was no mention of pedagogy (Gray, 2008, personal communication). This lack of explicit engagement with pedagogy is also characteristic of early years education. In 1999 Siraj-Blatchford described practitioners as 'recoiling' at the term pedagogy which they associated with teaching. Six years later the organisation in Scotland responsible for developing early years practice was aware of the need to tread cautiously if their plans to encourage practitioners to think about the theory and practice of learning and teaching were not to be rejected (Learning and Teaching Scotland, 2005). When we carried out a study designed to inform the development of a strategy for the use of technology in early years settings the questions we posed to practitioners about how they acted to support children's learning and how they knew that children were learning proved challenging (Plowman and Stephen, 2005). The study recommended that it was essential that a coherent and explicit pedagogical approach should be developed if the learning and teaching potential of the new resources was to be realised and if practice was not to be driven by technology rather than by the expertise of practitioners who understood children's learning patterns.

The Study of Pedagogical Effectiveness in Early Learning (SPEEL) Project began from the premise that the characteristics of effective pedagogy were embedded in practice and went on to attempt to identify and validate these characteristics (Moyles, Adams and Mosgrove, 2002). In the course of the SPEEL project the researchers found that

Most practitioners in looking at the video [of their practice] immediately identified features of a child's behaviour rather than their own, reactions to themselves often being at a very personal level rather than the level of identifying, for example professional knowledge or skills. Asked how she knew that the practice was effective, one early years teacher thought long and hard and then responded 'How do we know? We just know- we just do' Moyles et al., 2002, p 3, original italics

Moyles et al went on to argue that the expectation that children should engage in metacognitive processes should equally apply to practitioners and to warn that 'this inability to articulate [their own practices] may put a significant constraint upon effective pedagogical practices' (p. 3).

The reasons why practitioners are still reluctant to engage with pedagogical discussion or find it difficult to articulate the practices they adopt to support learning warrant further research. The roots of these reactions may lie in the development of early years provision with its dual purposes of compensatory nurture and care and planned support for physical, social and cognitive learning and development. The history of early years provision in the UK has given it a distinctive tradition, often accompanied by a desire to maintain an identity that is separate from that of schoolbased education. Nevertheless, as Moyles et al have pointed out, inhibitions about engaging in debate about pedagogy may hinder support for children's learning and may also limit professional growth.

\section{The Big Ideas: Child-centred Practices and Play}

Although there may be little evidence of explicit engagement in pedagogical discourse or thinking about the basis for practice development there are two enduring 'big ideas' that permeate thinking about practice and observable pedagogy in early years education in the UK. The first of these is concerned with provision that is childcentred and offers children ample opportunities to choose how to spend their time in the playroom and the second is the emphasis on play as the medium through which 
children learn. When Chung and Walsh (2000) reviewed the use of child-centredness in contemporary early childhood literature they found over 40 meanings of the term. These ranged from concerns with children's interests, through participation in decision-making to identifying and meeting 'potential'. When a concept is so variously interpreted it is difficult to sustain the argument that it is pivotal to the success of children's learning. Research evidence also offers a challenge to the common concern with child-centred practices and children's freely made choice of activity. Siraj-Blatchford and Sylva (2004) have demonstrated that it was settings where there was a balance between child-initiated and practitioner-initiated learning activities that were most effective in terms of children's cognitive, social and dispositional outcomes. Like Bowman, Donovan and Burns (2000), Siraj-Blatchford and Sylva point to the importance of sensitive and responsive support from adults who can manage the cognitive challenge that children experience and support 'sustained, shared thinking'.

Like the focus on child-centredness, the consensus view on the centrality of play is also challenged by the research literature. There are clear theoretical arguments about the contribution that play makes to learning and development through the opportunities if offers for children to experiment with meanings and rules (Vygotsky, 1967; Rogoff, 1990). On the other hand, empirical studies have pointed to the sometimes limited forms of play opportunities offered in educational settings and the under-development of the pedagogical role of the practitioner in children's play (e.g. Bennett, Wood and Rogers, 1997). As the British Educational Research Association (BERA) Early Years Special Interest Group (2003) pointed out in their review of the literature, 'the picture that emerges from research is that play in practice is problematic'. They pointed to the lack of evidence to support the often asserted relationship between play and learning, questioned the efficacy of 'free play' (where young learners choose from a range of activities and experiences) and described how play can be stereotypical and lacking in challenge. They concluded that

Whilst play forms the bedrock of early learning, an agreed pedagogy of play is less well articulated. . . The dominant ideology is not underpinned by systematic empirical research, and key studies both in preschool and in statutory school settings have identified significant gaps between the rhetoric and reality of practice. (BERA Early Years Special Interest Group, 2003 p 14).

Questioning play in early years education can be received as a challenge to a cornerstone of provision for the youngest children. But the time is ripe for a critical empirical and theoretical look at the contribution of play and an examination of what is perceived as play from the perspectives of all the stakeholders, including the children, involved in early years provision. It is important to recognise that looking critically at play does not imply a rejection of play as a crucial component in the learning environment. The purpose of reviewing the contribution of play is rather to strengthen its place as a medium for learning when that is most appropriate, to ensure that the play opportunities offered to children are playful and engaging to them and to develop a more nuanced and evidence-based rationale for play in the learning environment that is clear about the benefits and can go beyond an appeal to consensus and historic claims to distinctiveness.

\section{Pedagogical Practices: Influences and understandings}

The powerful consensus about the centrality of play and child-centred approaches to early years education can be expected to exert a significant influence on the ways in which practitioners act and think about their practice. However, these are but two of 
an array of influencing factors. Policy, curriculum and practice guidance, the experience of initial and continuing professional education, personal beliefs and value systems and the community of practice in which they work can all be expected to make a difference to what practitioners do and, therefore, to the experiences of children attending their setting.

The perspectives and practices encountered in the community of practice within which they work exert a powerful influence on the perspectives of practitioners. This influence is often implicit and shapes practitioners' tacit theories-in-action in ways that compete with or over-ride ideas encountered in initial or continuing professional education (Rosaen and Schram, 1998). Siraj-Blatchford (1999, p. 21) has suggested that practice was based on 'a consensus around an individualised play-based curriculum and that adults should be non-directive and only facilitate learning.' But this consensus assumes agreement on what is required to be an effective facilitator. The nature of the shared expectations and practices which are present across the public, private and voluntary sectors and different types of providers within sectors is an empirical question and one it seems timely to address in a systematic way through a co-ordinated programme of research.

In their conversations with practitioners Moyles et al (2002) found some evidence of the influence of the pioneers of preschool education and care (e.g. Froebel, Montessori, Isaacs, the McMillan sisters) and more frequent references to the approaches of High/Scope and Reggio Emilia as underpinning practice. But references to educational theorists were rare. Nevertheless, an examination of curricula and of playroom pedagogical practices provides some evidence of the legacy of Piaget. The ways in which children are grouped in playrooms by age suggests the influence of Piaget's linear, stage theory of development. Piaget's focus on the child's active exploration and movement through the processes of assimilation and accommodation can be seen in the emphasis that practitioners place on providing resource rich-environments and ample opportunities for children to explore as they choose. In their attention to acting as providers and observers who set up an environment, allow children to explore and experiment freely, observe, record and plan for the next opportunities it is possible to see practitioners adopting ideas from Piagetian theory.

However, there is a need for caution here. Piagetian theory has been subject to considerable challenge and modification from later research evidence (e.g.

Donaldson, 1978; James, Jenks and Prout, 1998) and it seems important that those who base their practice on these ideas (albeit implicitly) are aware of the caveats or revisions that researchers have identified, and which key aspects of the theory are considered to remain as a robust contribution to our understanding of children's learning. There is also a need to guard against practices designed to allow children space to explore tipping over into a laissez faire approach that removes adults from the learning process once the environment has been prepared and which can be seen as placing responsibility for progress and change on the young learner. Interplay set out to challenge the widespread belief (in the context of learning with technology at least) that free play is a sufficient condition for learning. We had witnessed failed or truncated encounters with technologies in the playroom. In some cases children could not complete the activity and left, in others they failed to explore the possibilities or could not get started on the activities, although all of these had been designed by adults to support learning through and about technology. Our observations of failed attempts at engagement suggested to us that a Piagetianderived focus on providing a richly resourced environment and opportunities for free exploration did not lead to the kind of sustained and purposeful encounters with technology that support learning. Our study went on to explore the pedagogic actions 
related to positive learning experiences but there is a need for more research to explore the implicit perspectives of practitioners, the impact of these views on practice and interactions with children and to engage practitioners in shared investigations of the efficacy of particular practices.

\section{Supporting learning with insights from socio-cultural theory}

An alternative set of theoretical influences comes from socio-cultural perspectives on learning (e.g. Vygotsky, 1978; Wertsch, 1985; Tharp and Gallimore, 1991). Adopting a socio-cultural perspective on learning means being concerned with the influence of the contexts in which children learn, how learning varies with social and cultural experiences and the ways in which adults, other children, tools and resources support and shape learning. For those who adopt the socio-cultural approach acting and thinking with others drives learning and at the heart of that process is dialogue and interaction. Indeed, perhaps the most ubiquitous pedagogical concept in academic and professional writing about children's learning from a socio-cultural perspective is scaffolding (Wood, Bruner and Ross, 1976). In their authoritative review of pedagogy and young children's learning Bowman, Donovan and Burns (2000) draw attention to the benefit that young learners get from the sensitive support of adults

Research from a variety of theoretical perspectives suggests that a defining feature of a supportive environment is a responsible and responsive adult. (Bowman, et al, 2000, Executive Summary, p 5).

In Interplay, our study of adults supporting children learning with technology, we set out to investigate the kinds of interactions that supported positive encounters with technology and were related to learning episodes. The practitioners' assessments of children and their records of learning episodes during the interventions demonstrated that children were learning about and through technology. Their accounts of children learning with technology fell into three categories: learning operational skills; learning about the world and developing cognitive capacities; and developing positive learning dispositions. We conceptualised the kind of pedagogy necessary to support this learning with technology as guided interaction. The interactions might be between the learner and an adult or more able peer, with the technology or other aspects of the environment, however, in this paper the focus is on interactions with or mediated by practitioners. Our analysis of video evidence, field notes, interviews and practitioner-generated evidence identified both distal and proximal forms of practitioner guided interaction supporting learning.

Distal guided interaction is indirect. It happens when children are not present but our evidence suggests that it is nevertheless influential and an important part of the support for learning. In the Interplay settings distal guided interaction included arranging access to the technologies, planning and ensuring that the resources used were appropriate (see Table 1 for examples).

\section{Table 1 Distal Guided Interaction about here}

Two levels of socio-cultural mediation are evident in Table 1. Through their indirect actions practitioners play a mediating role, guiding the kind of technology which children engage with, arranging the environment to offer optimum support for positive learning encounters and deploying their own resources to make possible the necessary proximal interactions. The second level of socio-cultural mediation comes through the policies and expectations of practice which influence the behaviour and 
decisions of practitioners, particularly in terms of planning and monitoring. The mediating influence of policy expectations and local or national practices is not always considered when pedagogy is discussed (Goouch, 2008) but it is an area for further study that should be included in the agenda for early years research. Other forms of distal guided interaction were practice driven and the result of practitioners' cumulated experience of playroom behaviour and management, for instance managing turn taking to ensure equitable access. A focus on scaffolding or working in the zone of proximal development as it is often constructed would not include these distal dimensions. Yet our data suggest that they make a difference to children's learning and point to the importance of thinking beyond the immediate inter-personal interaction to the ways in which the local cultural expectations impact on children's experiences and outcomes.

Pedagogy enacted through proximal or direct guided interaction is a more familiar construction in socio-cultural theorising. Examples of the forms of proximal guided interaction identified during the course of Interplay are set out in Table 2.

\section{Table 2: Proximal Guided Interaction about here}

Proximal guided interaction is concerned with the direct actions of adults as they engage with children to support their progress to new levels of knowing and acquisition of the cultural tools of their society. However, a distinctive feature of the instances of guided interaction we observed is the range of modalities in which they were enacted. The examples included in Table 2 involve physical actions, spoken language, touch, non-verbal gestures and emotional engagement. This multi-modal array of pedagogical actions goes beyond the support for task achievement through language that is more conventionally associated with scaffolding. Explored in this way the emotional and social aspects of pedagogical interactions are made evident, particularly in their contribution to developing positive learning dispositions. As the examples in Table 2 suggest, sharing a child's pleasure and fun or anxiety and fear can make important contributions to their persistence, confidence and engagement. But these 'emotional interactions' are not always considered in discussions about effective pedagogy, despite the importance of intersubjectivity in the learning process demonstrated by researchers working in the socio-cultural tradition e.g. Rogoff, 1990; Rommetveit (2003) and Trevarthen (1979). This remains an area which is under-developed in empirical work on young children's learning.

While it is not unusual to encounter references amongst practitioners and in practice guidance to co-construction of knowledge and to the value of adults and children learning together, discussions about how and when to scaffold, and what kinds of adult actions and interactions move children to new understandings and competencies with the tools of their society are less common. However, Interplay practitioners did not necessarily think about their practice in terms that could be construed as concerned with scaffolding or guiding children's interactions with adults, peers or the technological resources. Although they were frequently observed employing these forms of guided interaction as they worked with individual children or small groups, practitioners often had to be prompted by the research team to identify these kinds of behaviours as pedagogical actions (Stephen \& Plowman, 2008). They were more likely to see demonstrating how to use the paintbrush tool in an art programme, modelling using a mobile phone to order a taxi or prompting a child to type in her name as 'just something that we do' and which was taken for granted. I want to suggest that this taken for granted nature of pedagogic actions contributes to the apparent reluctance of practitioners to talk about their own pedagogic approach. The construction of their own behaviour as instinctive may lead 
early years practitioners to undervalue the contribution which their actions make to children's learning and also limit the opportunities for enhancing practice that can be derived from reflection on actions and interactions in the early years playroom or classroom. Seen from a socio-cultural theory perspective, interactions with adults are a key ingredient in the learning process.

At its best scaffolding and guided interaction requires practitioners to be able to diagnose the child's current understanding and what she could achieve with particular kinds of adult support (working in the Zone of Proximal Development). Of course having opportunities to engage in the observation and analysis necessary for effective diagnosis has implications for staff deployment. In our snap-shot study of young children's experiences with technology in the playroom we found many more examples of reactive supervision (e.g. sorting out difficulties over turntaking or how to return to the appropriate place on a computer menu) than instances of practitioners acting, for instance, to support a child complete a game, develop a tentatively acquired concept or enhance their phonetic and rhyming skills (Plowman and Stephen, 2005). In busy playrooms practitioners may have to divide their attention between a number of activity areas and many children as well as the practical tasks necessary to ensure the smooth running of the setting, consultations with parents and the demands of observation and record-keeping. Decisions about distal practices such as how to deploy staff in order that they can offer effective support for learning make a difference to children's playroom experiences and outcomes. Exploring the implications of alternative policy and practice decisions requires systematic research activity and opportunities for practitioners and researchers to pool questions and share reflections.

\section{Experimenting with mutual understanding and structuring of learning}

Socio-cultural theory challenges practitioners and researchers to consider what formal educational settings can adopt from the ways in which children learn at home and in their community. Working in the socio-cultural tradition Rogoff (2003) draws attention to the ways in which learning is supported in different communities and to the two forms of guided participation which she identifies as central to learning: mutual bridging of meaning and mutual structuring of opportunities. Rogoff argues that these two processes are both fundamental to learning and development and are universal. Mutual bridging of meaning refers to the understanding that develops between people in interaction. As participants modify their perspectives in the light of the understanding of others and in order to achieve particular goals, development and learning occur. Mutual structuring happens as children and adults together determine the activities the young learners may experience and the activities in which they can participate directly (e.g. domestic and institutional routines, conversations, classroom events and play). Children exercise their agency or structure their learning through the choices they make and the adult activities to which they attend.

While practitioners are likely to be aware of the need to establish shared understanding with young children, achieving mutuality in the activities undertaken is more challenging. In traditional societies children learn to acquire the tools for thinking and acting through observation and participation in authentic tasks that are part of everyday life. The engaging power of authenticity is more difficult to achieve in the playroom of Western developed countries where the activities and resources are specifically designed for children and are removed from everyday life and objects (Stephen, Cope, Oberski and Shand, 2008). In UK playrooms and early years classrooms children typically use resources designed for their age group which often simulate the objects used by and actions of adults and older children. Harnessing the 
power of mutual engagement and participation in personally meaningful tasks to support both children's disposition to learn and the development of specific skills and understanding is an area ready for research and practice development and is likely to be best tackled by researchers and practitioners together.

The development of a pedagogical approach in Scotland known as 'active learning' offered opportunities for us to begin to explore the scope for mutual bridging of meaning and mutual structuring of opportunities. Active Learning has its origins in evidence that formal, didactic instruction and paper-based ways of responding in school-like settings offer no advantages to four- to six-year olds. Policymakers and the managers of provision are advocating a shift to a more experiential and learnercentred approach that 'engages and challenges children's thinking using real-life and imaginary situations' (Scottish Executive, 2007, p. 5). Practitioners are urged to take advantage of the 'opportunities for learning' which arise in spontaneous and planned play, exploration, children's experiences and 'focused learning and teaching'. The findings from our study of the implementation of an active learning approach in six Primary 1 classrooms have given us much to consider about the meaning of 'active' but it is the way that choosing and autonomy in learning are conceived and enacted in practice in these classrooms that is most relevant for this paper. We found that practitioners endorsed the active learning pedagogical rhetoric that espouses learning through meaningful activities and children's purposeful engagement but the reality of children's learning experiences was varied and there was not always evidence of the degree of change or pedagogical awareness on the part of the practitioners (all with teacher education qualifications) that might have been expected.

Practitioners saw the changes they had implemented as resulting in children being more engaged in and enthusiastic about learning and increasing in confidence and independence in the classroom. They argued that active learning was a more inclusive approach as all children were able to participate in the curriculum in some way. In addition, they suggested that moving to an active learning pedagogy was a better experience for the teachers themselves, particularly as it allowed them more time to spend with individual children. However, practitioners tended to talk about change in terms of the ways in which they were expected to structure or organise learning activities differently in their classrooms rather than in terms of changing their ways of interacting with young learners and there was no discussion of a research or theoretical basis of the changes being implemented. The children's perspectives offered a less whole-hearted endorsement of the pedagogical innovation. Their responses revealed that contrary to adult expectations children saw their time in the classroom as dominated by 'work', 'doing jobs' and following rules and routines, all adult-led or structured experiences. They did talk positively about some of the activities they were encouraged to engage with in the classroom or in adjoining areas but it was what they regarded as play that engendered the most enthusiasm. But play was associated with activities that children arranged for themselves, with being outside or with imaginative games. The children's description of the learning environment as they experienced it showed little influence of the active or mutual engagement with meaning or structuring of learning opportunities that the practitioners suggested they were supporting. From the children there was little sense of ownership, time spent in working with others or of engagement in tasks that seemed authentic and meaningful to them. The children seemed to have developed an understanding of learning as being the result of pencil and paper 'work' that was adult-directed and evaluated.

The data from the systematic observations also suggest that the mutuality and carefully meshed understanding between adult and children which Rogoff argues 
supports learning are difficult to achieve in group settings. The children's experiences varied across the six classrooms involved but they all experienced a mix of adultdirected time with the whole class and time in small groups allocated by their teacher to specific activities or tasks. Some of these activities were open, while others were closed with 'right answers' and some were didactic episodes with the practitioner attending to a small number of children in turn. Only in one of the classes did children have any opportunity to choose which activities to engage with at any particular time; elsewhere activities were prescribed by the practitioner and often rotated according to a strict timetable. Our observations suggest that while the children's forms of acting and responding covered a somewhat greater range during the periods when the class was distributed, the teachers' actions were very similar whether the class was distributed or gathered together. In both contexts there was little evidence of space or time for encounters that supported mutual bridging of meaning or mutual structuring of opportunities for learning between practitioners and children. Of course this is a demanding expectation for teachers and there is a role for practitioners, managers of provision and researchers to work together to explore the ways in which learning in the classroom can mobilise the value of mutual engagement and authentic, meaningful activities.

\section{In Conclusion}

In the course of this paper I have suggested areas for inclusion in an agenda for future research in early years education. The apparent hesitation that practitioners have in engaging with discussion about pedagogy, their own practices and the understandings that underpin their actions seem important topics for further study, along with gathering and marshalling empirical evidence on the contribution of childcentred practices and play to young children's learning. The ways in which the range of influences identified in this paper as shaping practitioners' actions impact on children's playroom experiences should be placed on the agenda too. I have suggested that, in particular, the implications of socio-cultural theory should be investigated and that this could be profitably carried out by practitioners and researchers working together. Here we have focused on evidence about distal and proximal interactions and the opportunities to establish mutual meaning and structuring of learning opportunities as a way of supporting learning but there is much more to explore, including how group early learning settings can be managed to allow these kinds of interactions.

In the discussion above the focus has been on professional practices and research evidence but it is important to acknowledge that what practitioners and researchers do will also be influenced by their values, just as the curriculum and investment in provision reflects the values of society in general and the aims of policymakers in particular. Debates about pedagogy need to take account of different ways of construing children and learning and the purposes of early years provision. Stengel (2000) has described teaching as being a moral and technical phenomenon and concludes that part of the difficulty with talking about pedagogy is that we have not yet developed a language for teaching that combines the 'language of technique' (what is effective) with the 'language of manner' (what is ethical, moral or caring).

In taking a critical look at the literature and our empirical evidence we have tried to avoid placing practitioners in a deficit position. Nevertheless, we have questions about the pedagogical approaches which we have observed and it seems crucial that practitioners and observers of practice should be able to talk about practice and pedagogy without this being construed as involving 'attack' or 'defence'. It seems easier for practitioners to engage in discussions about particular pedagogical actions or interactions than to articulate their pedagogical perspective. This may be a 
reflection of the theory/practice gap that bedevils all professional education. However, I suggest that without a well-developed understanding of the ways in which they can support children's learning, practitioners are ill-equipped to take on the competing demands they will encounter. The confidence which early years practitioners have in their own efficacy and professional status could be enhanced by moving towards a more ready recourse to the discourse of pedagogy.

Profitable discussions about research evidence and implementation of recommendations require an understanding on the part of researchers about how to present their evidence in ways that are accessible to and make sense to practitioners and respect their professionalism, while allowing the perspectives of all to be represented. The process of guided enquiry (outlined above in the context of Interplay) has much to offer in this regard, but in our experience it is more readily embraced by preschool practitioners than primary school teachers, perhaps because the former are more used to gathering diverse forms of evidence across the learning process.

In this paper I have argued that pedagogical understandings make a difference to practice and therefore to children's experiences, but if these understandings remain tacit they can inhibit the development and adoption of new approaches. In order to be able to engage with theoretical ideas about support for learning, practitioners need to be aware of the limitations and challenges to these theories. Researchers and practitioner educators need to work towards answering questions such as 'What does a socio-cultural perspective demand of practitioners?'. I have suggested that academics and practitioners involved in the early years should look again at ideas that are considered as fundamental. Practitioners and researchers working together to look at pedagogical practices and their impact on learning offers a way forward but does depend on developing relationships that allow for a critical look at practice, innovation and research.

\section{References}

Alexander, R. 2004. Still no pedagogy? Principle, pragmatism and compliance in primary education. Cambridge Journal of Education 34, no 1: 7-33.

Bennett, N., Wood, L. and Rogers, S. 1997. Teaching Through Play: Teacher's thinking and classroom practice. Buckingham: Open University Press.

Bowman, B. T., Donovan, M. S. and Burns, M.S. 2000. Eager to Learn: Educating Our Preschoolers. Washington DC: The National Academies Press. http://www.nap.edu/openbook.php?isbn=0309068363 accessed 30 April 2009.

British Educational Research Association Early Years Special Interest Group. 2003. Early Years Research: Pedagogy, Curriculum and Adult Roles, Training and Professionalism

http://www.bera.ac.uk/files/2008/09/beraearlyyearsreview31may03.pdf accessed 30 April 2009.

Chung, S. and Walsh, D.J. 2000. Unpacking child-centredness: a history of meanings. Journal of Curriculum Studies 32, no 2: 215-234.

Donaldson, M. 1978. Children's Minds. London: Fontana.

Goouch, K. 2008. Understanding playful pedagogies, play narratives and play spaces. Early Years 28, no 1: 93-102. 
Gmitrova,V., Podhajeck, M. and Gmitrov, J. 2009. Children's play preferences: implications for the preschool education. Early Child Development and Care 179, no 3: 339-351.

James, A., Jenks, C. and Prout, A. 1998. Theorizing Childhood. Cambridge: Polity Press.

Learning and Teaching Scotland. 2005. Lets talk about pedagogy,towards a shared understanding for early years education in Scotland. Glasgow: Learning and Teaching Scotland http://www.Itscotland.org.uk/lmages/talkpedagogy_tcm4193218.pdf accessed 30 April 2009.

Moyles, J., Adams, S. and Musgrove, A. 2002. SPEEL Study of Pedagogical Effectiveness. Department for Education and Skills, Research Report 363.

Plowman, L. and Stephen, C. 2005. Children, play, and computers in pre-school education. British Journal of Educational Technology 36, no 2: 145-157.

Plowman L. and Stephen, C. 2007. Guided interaction in pre-school settings. Journal of Computer Assisted Learning 23: 14-26.

Rogoff. B. 1990 Apprenticeship in Thinking Cognitive Development in Social Context. New York: Oxford University Press.

Rogoff, B. 2003. The Cultural Nature of Human Development. New York: Oxford University Press.

Rommetveit, R. (2003) On the Role of 'a Psychology of the Second Person' in Studies of Meaning, Language and Mind. Mind, Culture and Activity 10, no 3: 205218.

Rosaen, C. L. and Schram, P. 1998. Becoming a member of the teaching profession: Learning a language of possibility. Teaching and Teacher Education 17: 913-924.

Scottish Executive. 2007. Building the curriculum 2 active learning in the early years. Edinburgh: Scottish Executive.

Simon, B. 1981. Why no pedagogy in England? In Education in the eighties: the central issues, ed. B. Simon and W. Taylor, 124-145. London: Batsford.

Siraj-Blatchford, I. 1999. Early Childhood Pedagogy: Practice, Principles and Research. In Understanding Pedagogy and its Impact on Learning, ed. P. Mortimer, 20-45. London: Paul Chapman Publishing Ltd.

Siraj-Blatchford, I. and Sylva, K. 2004. Researching pedagogy in English preschools. British Educational Research Journal 30, no 5: 713-730.

Spodek, B. 1988. The implicit theories of early childhood teachers. Early Child Development and Care 38: 13-32.

Stengel, B. 2000. Pedagogical Response-ability. Paper presented at the American Association of Colleges of Teacher Education Annual Meeting, Chicago, Illinois, February, 2000. 
Stephen, C. 2003. What makes All-day Provision Satisfactory for 3- and 4-Year Olds? Early Child Development and Care 173, no 6: 577-588.

Stephen, C. Brown, S. and Cope P. 2001. Alternative Perspectives on Playroom Practice. International Journal of Early Years Education 9, no.3:193-205.

Stephen, C. Cope, P., Oberski, I. and Shand, P. 2008. 'They should try to find out what the children like': Exploring engagement in learning. Scottish Education Review 40, no 2: 17-28.

Stephen, C., Ellis, J and Martlew, J. 2009. Turned on to Learning Active Learning in Primary One. Applied Educational Research Scheme, Research Briefing 8. http://www.strath.ac.uk/qie/aerscd09/resources/AERS\%20Research\%20Brieifings/A ERS\%20research\%20brief8.pdf accessed 30 April 2009.

Stephen, C., McPake, J., Plowman, L. and Berch-Heyman, S. 2008. Learning from the Children: Exploring Preschool Children's Encounters with ICT at Home. Journal of Early Childhood Research 6, no 2: 99-117.

Stephen, C. and Plowman, L. 2008. Enhancing learning with information and communication technologies in pre-school. Early Child Development and Care 178, no 6: 637-654.

Tharp, R. and Gallimore, R. 1991. A theory of teaching as assisted performance. In Learning to Think ed. P. Light, S. Sheldon and M. Woodhead, 42 - 61. London: Routledge.

Trevarthen, C. (1998) The concept and foundations of infant intersubjectivity. In Intersubjective Communication and Emotion in Early Ontogeny, ed. S. Bräten, 15 46. Cambridge: Cambridge University Press.

Vytgotsky, L. 1978. Mind in Society: the development of higher psychological processes (trans.). Cambridge, MA: Harvard University Press.

Watkins, C. and Mortimer, P. 1999. Pedagogy: what do we know? In Understanding Pedagogy and its Impact on Learning, ed. P. Mortimer, 20-45. London: Paul Chapman Publishing Ltd.

Wood, D., Bruner, J. and Ross, g. 1976. The role of tutoring in problem solving. Journal of Child Psychology and Psychiatry 17: 89-100.

Wertsch, J. V. 1985. Vygotsky and the Social Formation of Mind. Cambridge, MA: Harvard University Press. 
Table 1 Distal Guided Interaction

\begin{tabular}{|l|l|l|l|}
\hline $\begin{array}{l}\text { Form of guided } \\
\text { interaction }\end{array}$ & Examples from Interplay & $\begin{array}{l}\text { Mediating } \\
\text { factors }\end{array}$ & $\begin{array}{l}\text { Learning } \\
\text { supported }\end{array}$ \\
\hline monitoring & planning child's return to activity & $\begin{array}{l}\text { policy } \\
\text { practice }\end{array}$ & $\begin{array}{l}\text { extending } \\
\text { knowledge; } \\
\text { learning } \\
\text { dispositions; } \\
\text { operational skills }\end{array}$ \\
\hline planning & $\begin{array}{l}\text { ensuring balance across the } \\
\text { curriculum } \\
\text { ensuring range of activities for each } \\
\text { child } \\
\text { identifying learning needs }\end{array}$ & policy & $\begin{array}{l}\text { extending } \\
\text { knowledge; } \\
\text { learning } \\
\text { dispositions }\end{array}$ \\
\hline providing resources & $\begin{array}{l}\text { making broader range of ICT } \\
\text { available } \\
\text { placing disposable camera in story } \\
\text { sacks for taking home }\end{array}$ & $\begin{array}{l}\text { policy } \\
\text { practice }\end{array}$ & policy \\
practice & $\begin{array}{l}\text { extending } \\
\text { knowledge, } \\
\text { learning } \\
\text { dispositions, } \\
\text { operational skills }\end{array}$ \\
\hline
\end{tabular}


Table 2: Proximal Guided Interaction

\begin{tabular}{|c|c|c|c|}
\hline $\begin{array}{l}\text { Form of guided } \\
\text { interaction }\end{array}$ & Examples from Interplay & Modality & $\begin{array}{l}\text { Learning } \\
\text { supported }\end{array}$ \\
\hline \multirow[t]{5}{*}{ demonstrating } & $\begin{array}{l}\text { placing hand over child's hand as she } \\
\text { moves cursor or clicks on icon }\end{array}$ & touch & \multirow{5}{*}{ operational } \\
\hline & how to frame a picture in viewfinder & touch; oral & \\
\hline & how to plug in electronic keyboard & $\begin{array}{l}\text { physical } \\
\text { action; oral }\end{array}$ & \\
\hline & $\begin{array}{l}\text { turning over pages of story as children } \\
\text { listen on audio tape }\end{array}$ & physical action & \\
\hline & waving hand in front of EyeToy & physical action & \\
\hline \multirow[t]{2}{*}{ enjoying } & $\begin{array}{l}\text { sharing pleasure in features such as } \\
\text { animation }\end{array}$ & oral; laughter & \multirow{2}{*}{$\begin{array}{l}\text { learning } \\
\text { dispositions } \\
\text { extending } \\
\text { knowledge, } \\
\text { learning } \\
\text { dispositions }\end{array}$} \\
\hline & moving to the music on a CD player & physical action & \\
\hline \multirow[t]{3}{*}{ instructing } & reading dialogue box on screen & oral & \multirow[t]{3}{*}{ operational } \\
\hline & tell child how to use digital camera & oral, gesture & \\
\hline & tell child to push button on tape player & oral & \\
\hline \multirow[t]{3}{*}{ providing feedback } & giving encouragement for efforts & oral & \multirow{3}{*}{$\begin{array}{l}\text { learning } \\
\text { dispositions }\end{array}$} \\
\hline & smiling as child types name on keyboard & $\begin{array}{l}\text { facial } \\
\text { expression }\end{array}$ & \\
\hline & $\begin{array}{l}\text { says 'That's beautiful' when child shows } \\
\text { picture on camera }\end{array}$ & oral & \\
\hline supporting & $\begin{array}{l}\text { stays close to child using video camera } \\
\text { for safety \& emotional support }\end{array}$ & $\begin{array}{l}\text { physical } \\
\text { presence }\end{array}$ & $\begin{array}{l}\text { learning } \\
\text { dispositions; } \\
\text { operational }\end{array}$ \\
\hline
\end{tabular}

